\title{
Can Volume Predict Bitcoin Returns and Volatility? A Quantiles-Based Approach ${ }^{*}$
}

\author{
Mehmet Balcilar`, Elie Bouri ${ }^{\star}$, Rangan Gupta ${ }^{\bullet}$ and David Roubaud^
}

\begin{abstract}
Prior studies on the price formation in the Bitcoin market consider the role of Bitcoin transactions at the conditional mean of the returns distribution. This study employs in contrast a non-parametric causality-in-quantiles test to analyse the causal relation between trading volume and Bitcoin returns and volatility, over the whole of their respective conditional distributions. The nonparametric characteristics of our test control for misspecification due to nonlinearity and structural breaks, two features of our data that cover 19th December 2011 to 25th April 2016. The causality-in-quantiles test reveals that volume can predict returns - except in Bitcoin bear and bull market regimes. This result highlights the importance of modelling nonlinearity and accounting for the tail behaviour when analysing causal relationships between Bitcoin returns and trading volume. We show, however, that volume cannot help predict the volatility of Bitcoin returns at any point of the conditional distribution.
\end{abstract}

Keywords: Bitcoin; Volume; Returns; Volatility; Nonparametric Quantile Causality. JEL Codes: C22, G15.

\footnotetext{
* We would like to thank the Editor, Professor Mallick, and two anonymous referee for many helpful comments. However, any remaining errors are solely ours.

* Department of Economics, Eastern Mediterranean University, Famagusta, via Mersin 10, Northern Cyprus, Turkey and Department of Economics, University of Pretoria, Pretoria, 0002, South Africa; IPAG Business School, Paris, France. Email: mehmet@mbalcilar.net.

- Corresponding author. USEK Business School, Holy Spirit University of Kaslik, PO BOX 446, Jounieh, Lebanon. Email: eliebouri@usek.edu.lb.

- Department of Economics, University of Pretoria, Pretoria, 0002, South Africa. Email: rangan.gupta@up.ac.za.

^ Montpellier Business School, Montpellier, France. Email: d.roubaud@Montpellier-BS.com.
} 


\section{Highlights}

- Examine causal relation between Bitcoin return/volatility and traded volume.

- Detect nonlinearity and structural breaks in the return-volume relationship.

- Misspecified linear causality test shows no evidence of causality.

- Use instead nonparametric causality in quantile test.

- Reveal that volume can predict returns, but not volatility, at some quantiles.

\section{Introduction}

Studying the volume-return relationship is important to an understanding how information is transmitted to the market and embedded in asset prices. It also helps in increasing the power of forecasting asset return and volatility. In times of stress, in particular, it is central to examine the return-volume relationship to better understand market booms and crashes (Marsh and Wagner, 2000).

While the volume-return relationship has been extensively uncovered in equities (Karpoff, 1987; Li et al., 2016), bonds (Balduzzi et al., 2001), commodities (Chiarella et al., 2016), and interest rate and currency future (Puri and Philippatos, 2008), it remains unexplored in the Bitcoin market. The latter has recently attracted the attention of the media and scholars given the rising importance of Bitcoin not only as an electronic payment system but also as a financial and speculative asset (Kristoufek, 2014).

In a speculative market such as that of Bitcoin, understanding the volume-return is essential to shed lights on market efficiency and its potential implications on trading strategies. Practically, if the transaction volume in the Bitcoin market has predictive power on return, this provides evidence of weak-form inefficiency and thereby practitioners will be able to construct volume-based strategies to increase their profits (Chen et al., 2001). This is particularly important given that several traders and practitioners have been relied on technical analysis as an alternative tool to study Bitcoin prices because no reliable fundamental valuation techniques are available for quantifying the intrinsic value of Bitcoin. The fact that market technicians employ models 
and trading rules based the relation between return and volume further motivates a better understanding of the Bitcoin volume-return relationship.

Since its inception in 2009, Bitcoin has been characterized by sharp upward and downward price movements associated with high transaction volumes. On November 19, 2013, the price of Bitcoin on Bitstamp, the largest European Bitcoin exchange, plunged 19.88\% on the highest volume ever recorded (71,560 Bitcoins). Furthermore, on December 7, 2013, the Bitcoin price plunged $14.92 \%$ and recorded a new all-time high volume of 79,852 Bitcoins. Again, on December 18, 2013, Bitcoin price plunged $22.80 \%$ and hit new daily volume record high of 137,070 Bitcoins ${ }^{1}$. These features suggest a strong relationship between the magnitude of price movements and transaction volumes. However, no insightful work has been done so far to uncover this relationship in Bitcoin. To address this literature gap, we use a novel nonparametric causality-in-quantiles test of Balcilar et al. (2016a, b) to examine the predictability of Bitcoin returns and volatility based on trading volume. For our purpose, we use daily data covering the period of 19th December, 2011 to 25th April, 2016. The nonparametric causality-in-quantiles test combines elements of the test for nonlinear causality of $k$-th order developed by Nishiyama et al. (2011) with the causality-in-quantiles test developed by Jeong et al. (2012) and, hence, can be considered to be a generalization of the former. The causality-in-quantile approach has the following three novelties: Firstly, it is robust to misspecification errors as it detects the underlying dependence structure between the examined time series, which could prove to be particularly important as it is well known that stock returns display nonlinear dynamics (see Bekiros et al. 2016, for a detailed discussion in this regard) - a fact we show to holds in our data. Secondly, via this methodology, we are able to test not only for causality-in-mean (1st moment), but also for causality that may exist in the tails of the joint distribution of the variables, which in turn, is important if the dependent variable has fat-tails - something we show below to exist for 
Bitcoin returns (and volume). Finally, we are also able to investigate causality-in-variance and, thus, study higher-order dependency. Such an investigation is important because, during some periods, causality in the conditional-mean may not exist while, at the same time, higher-order interdependencies may turn out to be significant.

Note that we could have also used nonlinear causality tests (for example, Hiemstra and Jones, 1994, and Diks and Panchenko, 2005) and GARCH models to analyse the impact of volume on Bitcoin returns and/or volatility, as used recently by Bampinas and Panagiotidis (2015) while analyzing causality between gold and oil markets. As pointed out by Diks and Panchenko (2005), Himestra-Jones test is generally not compatible with the definition of Granger causality and over-rejects the null of no Granger causality. Diks and Panchenko (2005) rectify the over-rejection problem of the Himestra-Jones test by using the average of local dependence measures. However, these approaches rely on conditional-mean based estimation, and hence, fail to capture the entire conditional distribution of returns and volatility - something we can do with our nonparametric causality-in-quantile approach. Indeed, Bampinas and Panagiotidis (2015) find evidence that mean-based test cannot deal with the time dependent causality linkages due to structural breaks. In the process, our nonparametric causality-inquantiles test is a more general procedure of detecting causality in both returns and volatility simultaneously at each point of their respective conditional distributions. Hence, we are able to capture existence or non-existence of causality at various states of the Bitcoin market: bear (lower quantiles), normal (median), and bull (upper quantiles). As a more general test, our nonparametric causality-in-quantile approach is more likely to pick up causality when conditional mean-based tests might fail to do so. In addition, since we do not need to decide on the number of regimes as in a Markov-switching model, and can test for causality at each point of the conditional distribution characterising specific regimes, our test also does not suffer from any misspecification in terms of specifying and testing for the optimal number of regimes. An 
important issue however, is that like standard causality tests, existence of causality would imply that it holds at all horizons. As discussed in Bampinas and Panagiotidis (2015), a more informative causality test would be to use the approach of Hill (2007), which allows us to detect causality in tri-variate system and at multiple horizons and in a time-varying fashion using recursive or rolling windows. While the advantages in terms of multiple-horizons are undeniable, the approach of Hill (2007) remains a conditional mean based approach restricted to only the first-moment.

Indeed, there are studies like Chuang et al., (2009), Chiang and Li (2012), Gebka and Wohar (2013), Lin (2013) and Chen et al., (2016) that have used quantile based methodologies to study the relationship between returns and volatility with volume of traditional stock indices of Pacific Basin and Asian countries. However, to the best of our knowledge, this is the first paper that analyzes the predictability of returns and volatility of Bitcoin using trading volume based on a nonparametric method that covers the entire conditional distribution of returns and volatility, and also is free from misspecification due to nonlinearities and structural breaks..

The rest of the paper is organized as follows: Section 2 reviews the related literature on the finance and economics of Bitcoin. Section 3 presents the methodology, while Section 4 discusses the data and the results. Finally, Section 5 concludes.

\section{Literature Review}

Bitcoin is an open source software-based online payment system. Its popularity among practitioners and economic actors has soared in response to the perceived failures of governments and central banks during the global financial crisis of 2008 and the European sovereign debt crisis (ESDC) of 2010-2013. While central authorities and central banks guarantee or have control over conventional currencies, Bitcoin is fully decentralized and depends on a sophisticated protocol that uses only cryptography to control transactions, manage 
its supply, and prevent harmful actions that may endanger the system. All transactions are stored digitally and recorded in a shared ledger data technology known as blockchain. While the algorithm behind Bitcoin represents a solid safeguard against counterfeiting, the system has proved to be vulnerable to illicit activities such as the massive theft of 350 million USD worth of Bitcoins from the Mt. Gox exchange in February 2014. The principles of Bitcoin are explained by Dwyer (2015) and at bitcoin.org. Bitcoin is the first cryptocurrency to come into existence. While other cryptocurrencies, such as Feathercoin and Peercoin, now exist, Bitcoin has managed to maintain its leading position in this particular market. ${ }^{2}$ At the end of June 2016, Bitcoin market capitalisation exceeded 10 billion USD (coinmarketcap.com), which represents more than 80\% of the total market capitalisation of all cryptocurrencies on the market.

In addition to the early, extensive literature on the technical and legal aspects of Bitcoin, the economics and finance debate on Bitcoin have recently intensified. Kristoufek (2014) argues that Bitcoin represents a unique asset, possessing properties of both a standard financial asset and a speculative one. On the other hand, Popper (2015) considers Bitcoin to be digital gold and Bouri et al., 2017a ; Bouri et al., 2017b highlight some valuable characteristics of Bitcoin as an investment. Regardless of whether Bitcoin is a financial or a speculative asset, digital gold, or a commodity, some studies have been interested in the 'moneyness' of Bitcoin. Yermack (2013) argues that Bitcoin has no intrinsic value but behaves more like a speculative investment than a currency because its market capitalisation is high compared to the economic transactions it facilitates. The author also concludes that Bitcoin volatility adversely affects its usefulness as a currency. Glaser et al. (2014) find that most of the interest in Bitcoin is due to its 'asset' aspect and not its currency aspect. Hanley (2013) also indicates that Bitcoin has no fundamental value to support its pure market valuation against conventional currencies. In contrast, Woo et al. (2013) argue that Bitcoin has some fair value due to its money-like properties. Garcia et al. (2014) 
and Hayes (2016) show that the cost of producing a Bitcoin via mining adds some fundamental value to Bitcoins.

Other studies have examined the price formation in the Bitcoin market. Kristoufek (2013) reports a strong bidirectional causality between the prices of Bitcoin and the search queries for Bitcoin on Google Trends and Wikipedia. Bouoiyour and Selmi (2015) illustrate the significant role of a lagged Google search for the word 'Bitcoin' in explaining the Bitcoin price, whereas the velocity of Bitcoin, measured by data transactions, fails to explain the Bitcoin price. Similar results regarding the roles of the two above-mentioned variables (the volume of daily searches for Bitcoin on the Internet and the number of Bitcoin transactions) in explaining the Bitcoin price are reported by Polasik et al. (2015). Within the same research subject, Kristoufek (2014) finds that the trade-exchange ratio plays an essential role in driving Bitcoin price fluctuations in the long run. Bouoiyour et al. (2015) examine the relations between Bitcoin price and transactions proxied by the exchange-trade ratio. The authors find that Bitcoin price Granger causes an exchange-trade ratio in the short- and medium-terms. Like Kristoufek (2014), they find that the increasing use of Bitcoin in the exchange-trade ratio expands Bitcoin's price in the long term. They also show a significant link that runs from the exchange-trade ratio to the Bitcoin price. An interesting paper by Ciaian et al. (2016) focuses on the determinants of Bitcoin price fluctuations. It shows that the total number of unique Bitcoin transactions per day - a demand side variable - has more impact on the Bitcoin price than the number of Bitcoins - a supply side variable.

We argue that the above literature presents an incomplete picture of the role of trading volume in predicting the Bitcoin returns because the Bitcoin volume-return relationship at the tails may be different from that near the mean of the return distribution. Furthermore, prior studies have overlooked the dependency between the second moment of Bitcoin returns and trading volume. 
These issues suggest the appropriateness of using the nonparametric causality-in-quantiles test of Balcilar et al. (2016a) to investigate this further.

\section{Methodology}

In this section, we present a novel methodology for the detection on nonlinear causality via a hybrid approach developed by Balcilar et al. (2016), which in turn, is based on the frameworks of Nishiyama et al. (2011) and Jeong et al. (2012). This approach is robust to extreme values in the data and captures general nonlinear dynamic dependencies.

We start by denoting Bitcoin returns by $y_{t}$ and the predictor variable (in our case the traded volume) as $x_{t}$

Let $Y_{t-1} \equiv\left(y_{t-1}, \ldots, y_{t-p}\right), X_{t-1} \equiv\left(x_{t-1}, \ldots, x_{t-p}\right), Z_{t}=\left(X_{t}, Y_{t}\right)$ and $F_{y_{t} \mid Z_{t-1}}\left(y_{t}, Z_{t-1}\right)$ and $F_{y_{t} \mid Y_{t-1}}\left(y_{t}, Y_{t-1}\right)$ denote the conditional distribution functions of $y_{t}$ given $Z_{t-1}$ and $Y_{t-1}$, respectively. If we denote $Q_{\theta}\left(Z_{t-1}\right) \equiv Q_{\theta}\left(y_{t} \mid Z_{t-1}\right)$ and $Q_{\theta}\left(Y_{t-1}\right) \equiv Q_{\theta}\left(y_{t} \mid Y_{t-1}\right)$, we have $F_{y_{t} \mid Z_{t-1}}\left\{Q_{\theta}\left(Z_{t-1}\right) \mid Z_{t-1}\right\}=\theta$ with probability one. Consequently, the (non)causality in the -th quantile hypotheses to be tested are:

$$
\begin{aligned}
& H_{0}: P\left\{F_{y_{t} \mid Z_{t 1}}\left\{Q\left(Y_{t 1}\right) \mid Z_{t 1}\right\}=\right\}=1, \\
& H_{1}: \quad P\left\{F_{y_{t} \mid Z_{t 1}}\left\{Q\left(Y_{t 1}\right) \mid Z_{t 1}\right\}=\right\}<1 .
\end{aligned}
$$

Jeong et al. (2012) employ the distance measure $J=\left\{\varepsilon_{t} E\left(\varepsilon_{t} \mid Z_{t-1}\right) f_{z}\left(Z_{t-1}\right)\right\}$, where $\varepsilon_{t}$ is the regression error term and $f_{z}\left(Z_{t-1}\right)$ is the marginal density function of $Z_{t-1}$. The regression error $\varepsilon_{t}$ emerges based on the null hypothesis in (1), which can only be true if and only if $E\left[1\left\{y_{t} \leq Q_{\theta}\left(Y_{t-1}\right) \mid Z_{t-1}\right\}\right]=\theta$ or, equivalently, $1\left\{y_{t} \leq Q_{\theta}\left(Y_{t-1}\right)\right\}=\theta+\varepsilon_{t}$, where $\mathbf{1}\{\rtimes\}$ is an indicator function. Jeong et al. (2012) show that the feasible kernel-based sample analogue of $\boldsymbol{J}$ has the following form:

$$
\hat{J}_{T}=\frac{1}{T\left(\begin{array}{ll}
T & 1
\end{array}\right) h^{2 p}} \sum_{t=p+1}^{T} \sum_{s=p+1, s \neq t}^{T} K\left(\frac{Z_{t 1} Z_{s 1}}{h}\right) \hat{t} \hat{s} .
$$

where $K(\cdot)$ is the kernel function with bandwidth $h, T$ is the sample size, $p$ is the lag order, and ${ }_{t}$ is the estimate of the unknown regression error, which is estimated as follows:

$$
\hat{}_{t}=1\left\{y_{t} Q\left(Y_{t 1}\right)\right\} .
$$


$\hat{Q}_{\theta}\left(Y_{t-1}\right)$ is an estimate of the $\theta^{\text {th }}$ conditional quantile of $y_{t}$ given $Y_{t-1}$, and we estimate $\hat{Q}_{\theta}\left(Y_{t-1}\right)$ using the nonparametric kernel method as

$$
\hat{Q}_{\theta}\left(Y_{t-1}\right)=\hat{F}_{y_{t} \mid Y_{t-1}}^{-1}\left(\theta \mid Y_{t-1}\right)
$$

where $\hat{F}_{y_{t} \mid Y_{t-1}}\left(y_{t} \mid Y_{t-1}\right)$ is the Nadarya-Watson kernel estimator given by

$$
\hat{F}_{y_{t} \mid Y_{t 1}}\left(y_{t} \mid Y_{t 1}\right)=\frac{{ }_{s=p+1, s t}^{T} L\left(\left(\begin{array}{lll}
Y_{t 1} & \left.Y_{s 1}\right) / h
\end{array}\right) 1\left(\begin{array}{ll}
y_{s} & y_{t}
\end{array}\right)\right.}{T},
$$

with $L(\cdot)$ denoting the kernel function and $h$ the bandwidth.

In an extension of Jeong et al. (2012)'s framework, we develop a test for the second moment. In particular, we want to test the volatility causality running from the traded volume to Bitcoin returns. Adopting the approach in Nishiyama et al. (2011), higher order quantile causality can be specified as:

$$
\begin{array}{ll}
H_{0}: \quad P\left\{F_{y_{t}^{k} \mid Z_{t 1}}\left\{Q\left(Y_{t 1}\right) \mid Z_{t 1}\right\}=\right\}=1 & \text { for } k=1,2, \ldots, K \\
H_{1}: \quad P\left\{F_{y_{t}^{k} \mid Z_{t 1}}\left\{Q\left(Y_{t 1}\right) \mid Z_{t 1}\right\}=\right\}<1 & \text { for } k=1,2, \ldots, K
\end{array}
$$

Integrating the entire framework, we define that $x_{t}$ Granger causes $y_{t}$ in quantile $\theta$ up to the $k^{\text {th }}$ moment using Eq. (7) to construct the test statistic of Eq. (6) for each $k$. The causality-invariance test can be calculated by replacing $y_{t}$ in Eqs. (3) and (4) with $y_{t}^{2}$. However, it can be shown that it is not easy to combine the different statistics for each $k=1,2, \ldots, K$ into one statistic for the joint null in Eq. (11), because the statistics are mutually correlated (Nishiyama et al., 2011).To efficiently address this issue, we include a sequential-testing method as described Nishiyama et al. (2011). First, we test for the nonparametric Granger causality in the first moment (i.e. $k=1)$. Nevertheless, failure to reject the null for $k=1$ does not automatically leads to nocausality in the second moment. Thus, we can still construct the tests for $k=2$.

The empirical implementation of causality testing via quantiles entails specifying three important choices: the bandwidth $h$, the lag order $p$, and the kernel type for $K(\cdot)$ and $L(\cdot)$ respectively. In this study, we make use of lag order of 7 based on the Schwarz Information Criterion (SIC) under a VAR involving Bitcoin returns and traded volume. Moreover, when it comes to choosing lags, the SIC is considered being parsimonious compared to other lag-length selection criteria. The SIC helps overcome the issue of overparametrization usually arising with 
nonparametric frameworks. ${ }^{2}$ The bandwidth value is chosen by employing the least squares cross-validation techniques. ${ }^{3}$ Finally, for $K(\cdot)$ and $L(\cdot)$ Gaussian-type kernels was employed.

\section{Data and Empirical Findings}

\subsection{Data}

In this study, we use two variables, namely, the Bitcoin index and the trading volume as a measure the level of trading activity. The Bitcoin price index is denominated in USD, the currency against which Bitcoin is the most traded on Bitstamp - the largest European Bitcoin exchange (Brandvold et al., 2015). Daily price and volume data for Bitcoin traded on Bitstamp are sourced from: www.bitcoincharts.com.

Both the Bitcoin index and volume are non-stationary in log-levels as indicated by standard unit root tests. ${ }^{5}$ Since our methodology requires stationary data, we work with Bitcoin returns, obtained as the first-differences of the natural logarithmic values of the index expressed in percentage. The squared values of returns measure the volatility of the Bitcoin returns. Previous studies have shown the existence of deterministic time trends, both linear and nonlinear, in the volume data (Gallant et al., 1992; Chen et al., 2001 ; Gebka, 2012). To control for these trends, and following Gebka and Wohar (2013), we use a detrended measure of volume. Specifically, we consider the natural log of the volume series and remove its trend by regressing it on a constant, $(t / T)$ and $(t / T)^{2}$, where $T$ is the total sample size. Our period of analysis covers the daily period of 19 December 2011 to 25 April 2016 (i.e. 1587 observations). ${ }^{6}$ Interestingly, the sample period covers the Bitcoin crash of December 2013 (Cheah and Fry, 2015) and the recovery that started in the fourth quarter of 2014. Thus, as a result, it allows us to examine how the return-volume relationship in the Bitcoin market was affected. 
Table 1 presents the descriptive statistics for the Bitcoin returns and traded volume. We observe that volume is more volatile than returns in the Bitcoin market. More importantly, for our context of causality-in-quantiles, both the variables are skewed to the left, with excess kurtosis, resulting in non-normal distributions (see also the results from the Jarque-Bera test). The heavy-tails in the distributions of both the returns and the volume further confirm our choice of employing a causality-in-quantiles test. Furthermore, results from the Augmented Dickey-Fuller (ADF) test show that the two series are stationary.

Table 1. Summary Statistics

\begin{tabular}{|c|c|c|}
\cline { 2 - 3 } \multicolumn{1}{c|}{} & \multicolumn{2}{c|}{ Variable } \\
\hline Statistic & Returns & $\begin{array}{c}\text { (Detrended) } \\
\text { Volume }\end{array}$ \\
\hline Mean & 0.0031 & 0.0013 \\
\hline Median & 0.0020 & 0.0554 \\
\hline Maximum & 0.3375 & 2.7966 \\
\hline Minimum & -0.6639 & -6.6199 \\
\hline Std. Dev. & 0.0516 & 0.9022 \\
\hline Skewness & -1.6387 & -0.7632 \\
\hline Kurtosis & 28.8730 & 6.7148 \\
\hline $\begin{array}{c}\text { Jarque- } \\
\text { Bera }\end{array}$ & 44975.1100 & 1066.5960 \\
\hline Probability & 0.0000 & 0.0000 \\
\hline
\end{tabular}

Note: Std. Dev. stands for standard deviation. For Jarque-Bera test, the null hypothesis is of normality. For Augmented Dickey fuller (ADF) test, the null hypothesis is that the series has a unit root.

The natural logarithm of the data for the Bitcoin index and traded volume, and their respective transformations to returns and detrended volume, are presented in Figure 1. We clearly notice the long bull market that lasted almost three years before it ended in December 2013 - the month during which we captured a major structural break in Bitcoin prices (see the next sub-section for more details), with such an observation also made by Bouri et al., (2016). 
Fig. 1. a). Natural logarithm of closing price of Bitcoin. b). Natural logarithm of volume traded. c). Bitcoin returns. d). Detrended volume.
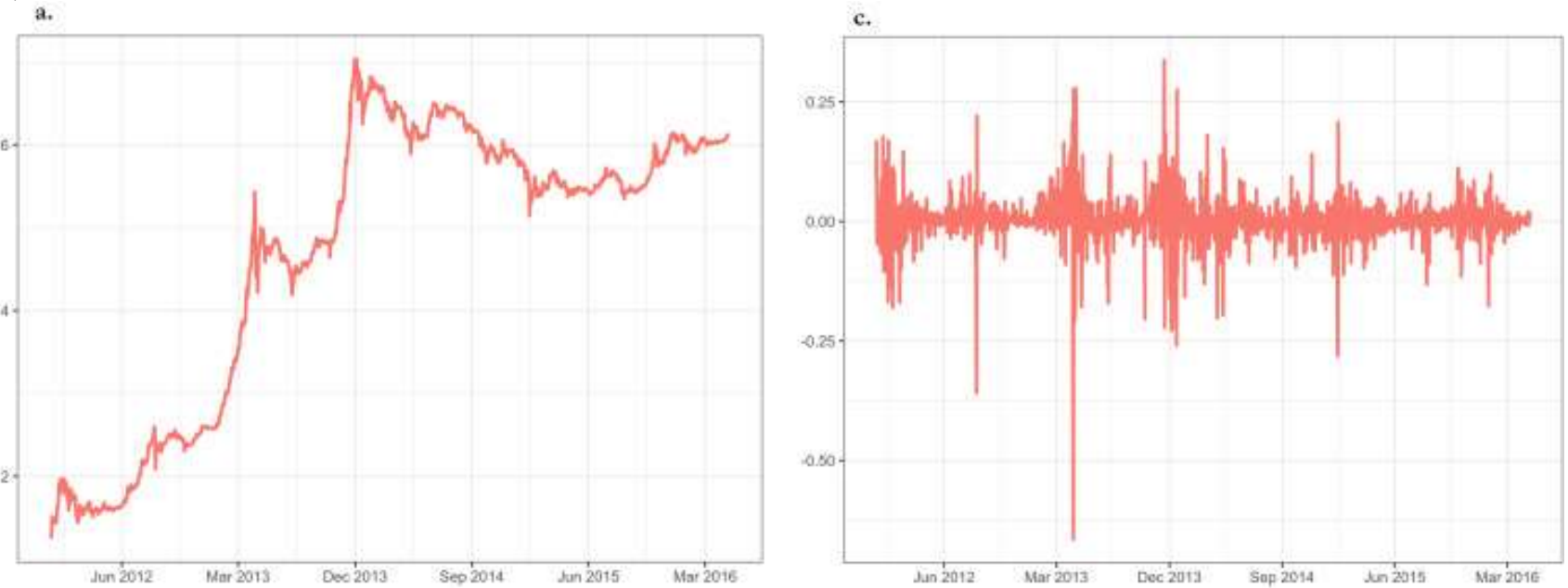

b.
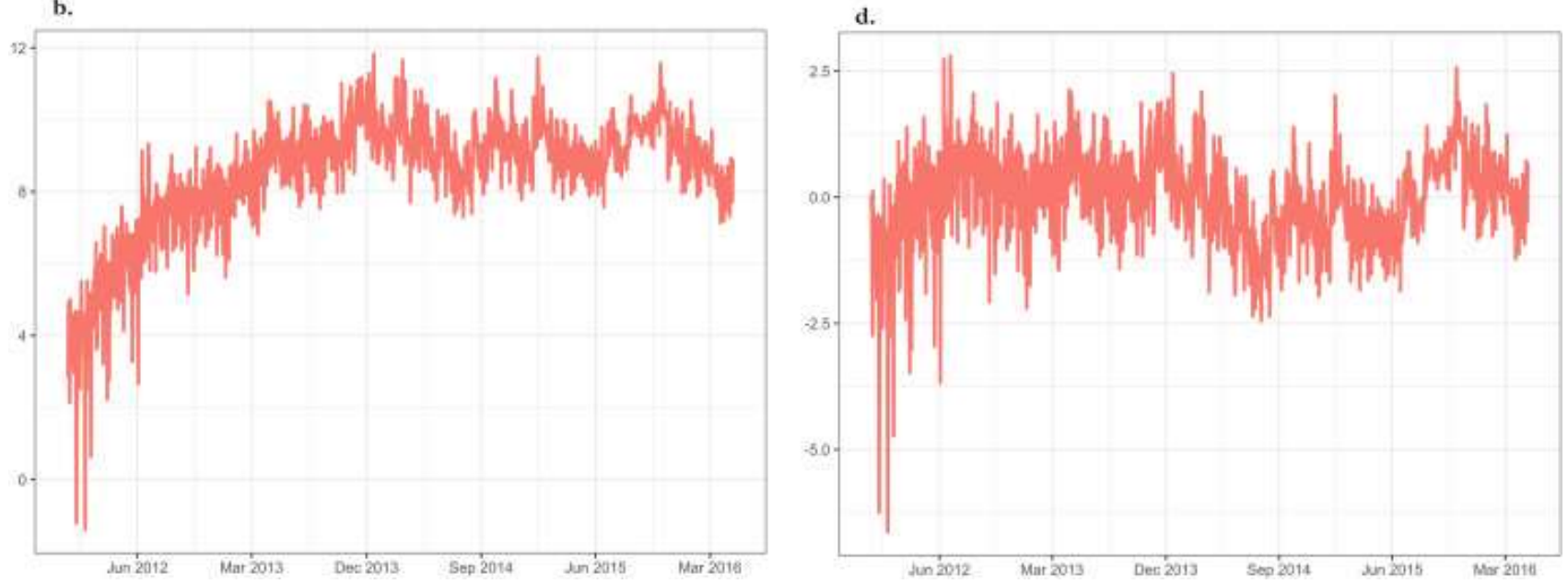

Fig. 2 provides a scatterplot of Bitcoin returns against the detrended volume. In Fig. 2, we also present the fit from a local polynomial regression (LOESS) with polynomial degree 2 (solid line). The shaded region in Fig. 2 denotes the 95\% confidence band for the LOESS fit. The LOESS fit in Fig. 2 is indicative of no relationship between the detrended volume and Bitcoin returns. However, the relationship of the return dispersion with the detrended volume level in Fig. 2 indicates a positive relationship between the return volatility and the level of the detrended volume. 
Fig. 2. Scatterplot of Bitcoin returns against detrended volume. Note: The fit from a local polynomial regression (LOESS) with polynomial degree 2 is denoted with the solid line. Shaded region denotes the 95\% confidence band for the LOESS fit. Grey vertical dashed lines are drawn at the 0.18 (at value -0.78 ) and 0.80 (at value 0.85 ) quantiles of the detrended volume.

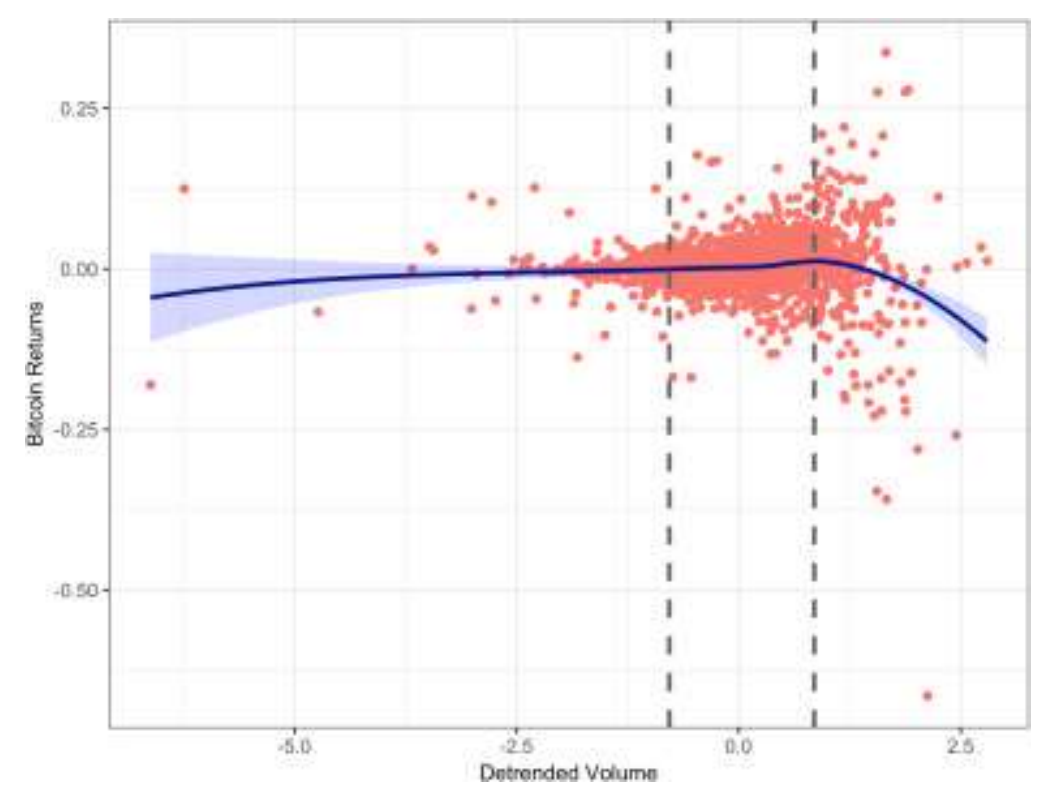

\subsection{Empirical Findings}

Before conducting the causality-in-quantiles tests running from volume to the Bitcoin returns and their volatility, we first present the results from the standard linear Granger causality test based on a $\operatorname{VAR}(7)$ model. The resulting $\chi^{2}(7)$ statistic for the null that volume does not Granger cause returns is 9.4305 with a $p$-value of 0.2232 . In other words, volume cannot be used to predict Bitcoin returns based on the linear causality test even at the $10 \%$ level of significance.. ${ }^{7}$

Next, we examine whether the relationship between the Bitcoin returns and volume is non-linear in order to further confirm our reliance on the nonparametric quantile-in-causality approach. To this end, we apply the Brock et al. (1996, BDS) test on the residuals of an AR(7) model for returns, and the returns equation in the $\operatorname{VAR}(7)$ model involving traded volume. As can be seen from Table 2, based on 10,000 bootstrap replications, we find strong evidence, at the highest level of significance, for the rejection of the null of i.i.d. residuals at various embedded dimensions $(m) .{ }^{8}$ These results suggest the presence of nonlinearity in the returns as well as in 
the relationship between the returns and volume. Accordingly, the equation for testing the null of no-Granger causality in the linear model is misspecified and the results of the standard linear causality test are spurious. ${ }^{9}$

Table 2. BDS Test Statistic

\begin{tabular}{|c|c|c|c|c|c|}
\hline \multirow{2}{*}{$\begin{array}{c}\text { Model of Returns } \\
\text { Equation }\end{array}$} & $\mathbf{2}$ & $\mathbf{3}$ & $\mathbf{4}$ & $\mathbf{5}$ & $\mathbf{6}$ \\
\cline { 2 - 6 } & $12.9500^{* * *}$ & $15.5327^{* * *}$ & $17.4181^{* * *}$ & $19.1123^{* * *}$ & $20.9129^{* * *}$ \\
\hline AR(7) & & & & & $21.1136^{* * *}$ \\
\hline VAR(7) & $13.0976^{* * *}$ & $15.6403^{* * *}$ & $17.5329^{* * *}$ & $19.2779^{* * *}$ & 2 \\
\hline
\end{tabular}

Note: $m$ stands for the number of (embedded) dimension which embed the time series into $m$-dimensional vectors, by taking each $m$ successive points in the series. Values in the cells represent BDS $z$-statistic; ${ }^{* * *}$ indicates rejection of the null of i.i.d. residuals at 1 percent level of significance.

Now, we turn to the powerful UDmax and WDmax tests of Bai and Perron (2003). These determine 1 to $M$ (multiple) globally determined breaks with the error distributions differing across the breaks, applied again to the $\mathrm{AR}(7)$ model for Bitcoin returns, and the returns equation in the $\operatorname{VAR}(7)$ model involving the volume. There is only one break (19 December 2013) in the AR(7) model of returns that corresponds to the Bitcoin price crash of December 2013, identified in Cheah and Fry (2015). Two breaks (18 April 2013 and 18 December 2013) are detected for the returns equation in the $\operatorname{VAR}(7)$ model involving volume ${ }^{10}$ : the first corresponds to the Bitcoin bubble of April 2013 following the technical glitch in the Bitcoin software (Fry and Cheah, 2016); the second break of December 2013 as mentioned above, identified in the return series. The results from the BDS test show that the standard linear Granger causality test is misspecified. Furthermore, evidence of nonlinearity and regime changes in the relationship between returns and volume leads us to employ the causality-in-quantiles test. The latter, being a nonparametric (i.e. data-driven) approach, is robust to linear misspecification.

In Figure 3, we present the results obtained from the quantile causality test for Bitcoin returns and squared returns (i.e., volatility) due to the traded volume over the quantile-range of 
0.01 to $0.99 .^{4}$ As can be seen, the null that volume does not Granger cause returns is rejected, in general, at the five percent level of significance (critical value of 1.96) over the quantile range $(\tau)$ of 0.24 to 0.66 of the conditional distribution of returns. The causality is rejected consistently over 0.24 to 0.51 , i.e., from below the median till just above it. Predictability is then observed intermittently till the quantile 0.66 . However, we fail to reject the null of volume does not Granger cause volatility over the entire conditional distribution. ${ }^{5}$ In other words, volume can predict returns, but not volatility, with the evidence of causality for returns holding over the entire conditional distribution barring the two ends. Specifically speaking, volume has no predictive content for Bitcoin returns when the market is in bearish (lower quantiles) and bullish (upper quantiles) phases. But, when the market is functioning around the normal (median) mode, volume can indeed predict returns.

Figure 3. Causality-in-Quantiles: Volume does not Granger cause Bitcoin Returns and Volatility

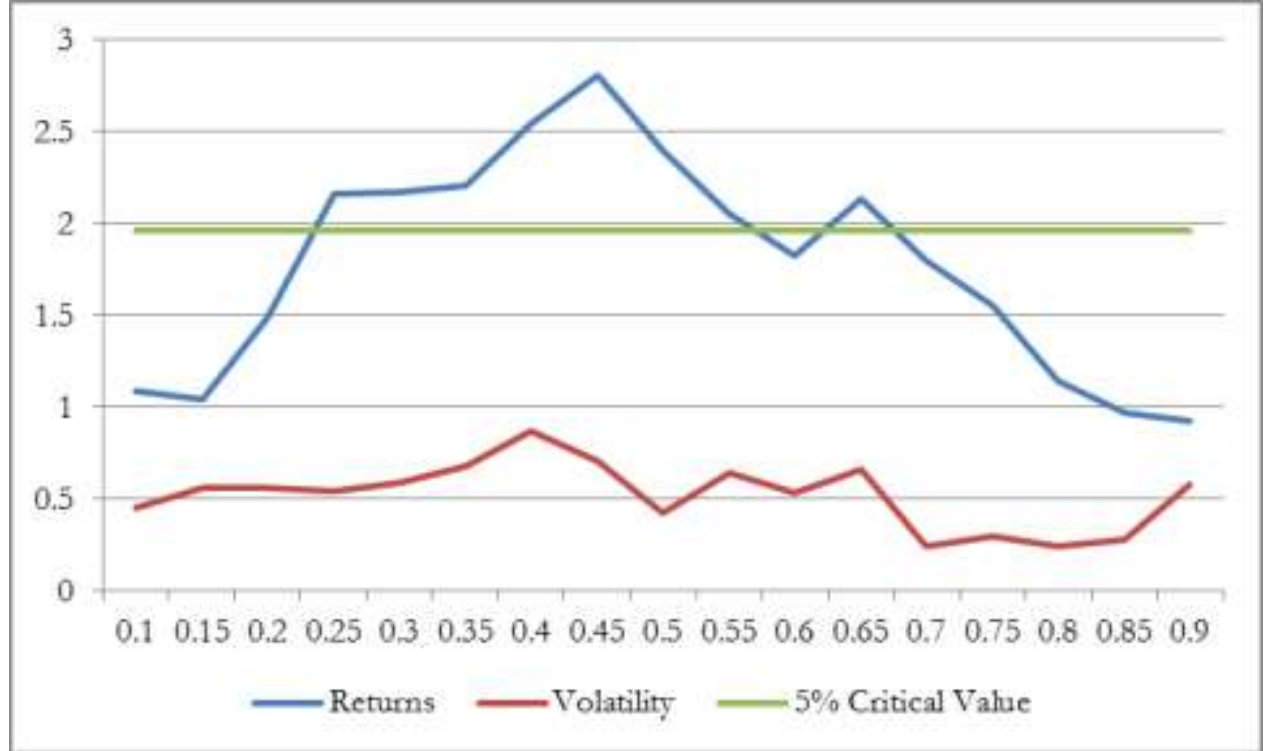

Note: Vertical axis presents the test statistics corresponding to the null the volume does not Granger cause returns, and volume does not Granger cause volatility; Horizontal axis measures the quantiles; 5 percent critical value is 1.96 . 
The findings from the causality-in-quantiles tests can be intuitively seen from Fig. 2 . The LOESS fit in Fig. 2 indicates no association between the Bitcoin returns and volume except at the very high end of the volume quantiles. The negative relationship at high values of detrended volume does not indicate significant test statistics as there are only a few observations at these high quantile ranges, leading to imprecise estimates. Fig. 2 also shows an increasing dispersion of Bitcoin returns with the level of the volume, particularly in the mid-ranges of the volume values. The insignificant test statistics at the $10 \%$ significance level for quantile causality in volatility in Fig. 3 corresponds to the quantile ranges below 0.18 (value of detrended volume equal to -0.78 ) and above 0.80 (value of detrended volume equal to 0.85 ), which are marked with dashed vertical lines in Fig. 2. We see from Fig. 2 that the relationship between the Bitcoin return dispersion and the level of the volume is weak in the quantile ranges below 0.18 and above 0.80 . Additionally, fewer observations fall into these quantile ranges. These two features lead to insignificant tests statistics presented in Fig. 3 for the causality in volatility.

Furthermore, we estimated a GARCH $(1,1)$ model for Bitcoin returns and extracted the resulting GARCH variance series. We then conducted the causality-in-quantiles test using this GARCH-based estimate of volatility. As can be seen in Fig. A1 in the Appendix A, we find that barring the extreme lower (0.01-0.09) and upper quantile ranges (0.97-0.99), volume predicts volatility over its entire conditional distribution, with the strongest predictability observed at quantile 0.72 . These results completely differ from those obtained using squared returns. However, we believe that since squared returns - as a measure of volatility - follow directly from the $k$-th order test, and are independent of a model-based estimate of volatility (which could vary depending on what model of volatility we choose), the use of squared returns is more appropriate in our context in capturing the risk involved in the Bitcoin market. Balcilar et al. (2016b) have also posited a similar line of reasoning. In light of this, we have presented the GARCH-based result of volatility in the Appendix A, and considered the model-free estimate of 
volatility using squared returns as a more robust estimate of Bitcoin market volatility. Naturally, the result based on squared returns is also more reliable; this is more so because we show that returns evolve in a nonlinear fashion, which the GARCH model does not take into account while capturing the volatility.

To summarize, evidence that volume predicts Bitcoin returns is non-existent in the linear model. However, this evidence is not robust to the presence of nonlinearity and structural breaks. We therefore employ the nonparametric causality-in-quantiles test, which is more appropriate and robust to misspecifications, and reveal that volume can predict returns around the median of the conditional distribution, but not volatility.

This result seems to suggest that investors in the Bitcoin market can obtain valuable predictive information for returns from traded volume, when the market is in normal mode. However, in bear and bull regimes, volume plays no role in predicting returns, with past (seven) lags of returns providing relatively more valuable information for future returns than volume. This finding partially implies that in stress periods, unlike in the case of equities, trading volume is not associated with extremely high/low returns in the Bitcoin market.

These findings on return predictability based on volume add to information documented in prior studies trying to define the underlying factors that determine the price of Bitcoin (Bouoiyour and Selmi, 2014; Bouoiyour et al., 2014; Polasik et al., 2014; Kristoufek, 2014; Ciaian et al., 2016). In fact, our findings provide a broader picture of the dependence between volume and returns in the Bitcoin market and uncover the insignificant role of trading volume in predicting Bitcoin price volatility. In terms of the finding of return predictability around the median, our result is different from what is observed in equity markets, where the predictability of returns from volume holds mostly at the tails (Chuang et al., 2009; Gebka and Wohar, 2013). This could possibly be due to the short-selling constraint in the Bitcoin market in the lower-end of the market. However, when the market is booming, there is more herding into the market and 
less interest in searching out relevant information (in this case on volume) on behalf of market agents. The lack of predictability of volatility from traded volume provides support to the socalled mixture of distribution hypothesis (MDH) developed by Clark (1973). MDH assumes that the volume-volatility relation is dependent on the rate of information flow into the market. The basic intuition is that because all traders simultaneously receive new information, there is no intermediate equilibrium. Since the variables contemporaneously change in response to new information, it is impossible to use past volume data to predict volatility. The possibility of $\mathrm{MDH}$ holding in the Bitcoin market rather than the sequential information arrival hypothesis (SIAH; Copeland, 1976) is likely to be higher due to possible easy dissemination of information across traders, given that Bitcoin involves an open source, software-based online payment system.

\section{Conclusion}

Although a large amount of literature has focused on the role of traded volume in predicting movement in stock returns and volatility (see Gebka and Wohar, 2013, for a detailed literature review), the predictability of traded volume for the returns and volatility in the Bitcoin market remains unexplored. To address this literature gap, we examine daily data covering the period of $19^{\mathrm{t}}$ December 2011 to 25 April 2016, which interestingly show that the Bitcoin returns and volume are non-normally distributed. Methodologically, we employ a novel nonparametric causality-in-quantiles test proposed by Balcilar et al. (2016a). It combines elements of the test for nonlinear causality of $k$-th order developed by Nishiyama et al. (2011) with the causality-inquantiles test proposed by Jeong et al. (2012).

Our results are summarized as follows: First, the standard linear Granger causality test, which was conducted for comparison purposes, fails to detect any evidence of volume causing 
returns. Second, the nonlinearity test indicates that returns and their relationship with volume evolve in a nonlinear manner. Additionally, tests of multiple structural breaks show evidence of regime changes in returns and in the equation relating them to volume. Evidence of nonlinearity and structural breaks suggests that the linear Granger causality is misspecified, thus, leading to unreliable results. Third, the causality-in-quantiles approach, which emerges as a suitable choice given evidence of non-linearity, structural breaks, and fat tails, reveals that the null that volume does not Granger cause returns is rejected at the conventional levels of significance over the quantile range of 0.25 to 0.75 of the conditional distribution of returns. However, we fail to reject the null that volume does not Granger cause volatility over the entire conditional distribution. These results show that volume can predict returns, but not volatility, with causality for returns non-existent in bearish (lower quantiles) and bullish (upper quantiles) phases. Therefore, when the market is functioning around the normal (median) mode, volume can indeed predict returns, thus providing investors in the Bitcoin market with valuable predictive information. However, when the market is performing well or poorly, all that matters for predicting future returns is past values, and thus information about volume is irrelevant. Generally, our results, via the volume-returns causality in the Bitcoin market, highlight the importance of detecting and modelling nonlinearity when analysing predictability via causal relationships. In the Bitcoin speculative market, our findings involve potential implications for trading strategies. Practically, under normal market conditions, practitioners and traders in the Bitcoin market will benefit from constructing volume-return based strategies to increase their profits. This evidence adds to prior studies that only associate Bitcoin price and transaction measures as well as search queries of Bitcoin on Google Trends and Wikipedia ( Kristoufek, 2013; Bouoiyour and Selmi, 2015 ; Ciaian et al., 2016). However, in the bear and bull phases of the Bitcoin market, practitioners and traders can still rely on technical analysis. 
Given our reliance on the Bitstamp exchange as the sole source of our data for analysing the predictability of Bitcoin returns and volatility based on traded volume, future research may assess whether our results hold in the context of data originating from other leading Bitcoin exchanges. With our approach being a bivariate approach, it would be interesting to check the robustness of our results for both in- and out-of-sample in a multivariate approach that includes other possible predictors such as the volume of daily searches for Bitcoin on the Internet and the mining cost of Bitcoin.

\section{References}

Bai, J. and Perron, P. (2003). Computation and analysis of multiple structural change models. Journal of Applied Econometrics 18, 1-22.

Balcilar, M., Gupta, R., Kyei, C., and Wohar, M.E. (2016a). Does Economic Policy Uncertainty Predict Exchange Rate Returns and Volatility? Evidence from a Nonparametric Causality-in-Quantiles Test. Open Economies Review, 27 (2), 229-250.

Balcilar, M., Gupta, R., Pierdzioch, C. (2016b). Does uncertainty move the gold price? New evidence from a nonparametric causality-in-quantiles test. Resources Policy, 49(1), 7480.

Balcilar, M., Gupta, R., Pierdzioch, C., and Wohar, M.E. (2016c). Terror Attacks and StockMarket Fluctuations: Evidence Based on a Nonparametric Causality-in-Quantiles Test for the G7 Countries. European Journal of Finance, doi: http://dx.doi.org/10.1080/1351847X.2016.1239586.

Balduzzi, P., Elton, E. and Green, T. (2001). Economic News and Bond Prices: Evidence from the U.S. Treasury Market. Journal of Financial and Quantitative Analysis, 36(4), 523-43.

Bekiros, S., Gupta, R., and Majumdar, A., (2016). Incorporating Economic Policy Uncertainty in US Equity Premium Models: A Nonlinear Predictability Analysis. Finance Research Letters, 18, 291-296.

Bouoiyour, J. and Selmi, R. (2015). What Bitcoin Looks Like? Annals of Economics and Finance, 16(2), 449-492. 
Bouoiyour, J., Selmi, R. and Tiwari, A. (2015). Is bitcoin business income or speculative foolery? new ideas through an improved frequency domain analysis. Annals of Financial Economics, 10, 1550002.

Bouri, E., Gil-Alana, L.A., Gupta, R., Roubaud, D. (2016). Modelling Long Memory Volatility in the Bitcoin Market: Evidence of Persistence and Structural Breaks. Department of Economics, University of Pretoria, Working Paper No. 2016-54.

Brandvold, M., Molnár, P., Vagstad, K., and Valstad, O. C. A. (2015). Price discovery on Bitcoin exchanges. Journal of International Financial Markets, Institutions and Money, 36, 1835.

Brock, W., Dechert, D., Scheinkman, J., LeBaron, B., 1996. A test for independence based on the correlation dimension. Econometric Reviews, 15, 197-235.

Cheah, E-T. and Fry, J. M. (2015). Speculative bubbles in Bitcoin markets? An empiricalinvestigation into the fundamental value of Bitcoin. Economic Letters, 130, $32-36$.

Chen, G.M., Firth, M. and Rui, O. (2001). The Dynamic Relation between Stock Returns, Trading Volume and Volatility. The Financial Review, 36(3), 153-174.

Chen, (Cathy) W.S., So, (Mike) K.P., and Chiang, (Thomas) C. (2016). Evidence of Stock Returns and Abnormal Trading Volume: A Threshold Quantile Regression Approach, 67(1), 96-124.

Chiang, T. C. and J. Li (2012) Stock Returns and Risk: Evidence from Quantile Regression Analysis, Journal of Risk and Financial Management, 5, 20-58.

Chiarella, C., Kang, B., Nikitopoulos, C. S., and To, T-D. (2016). The return-volatility relation in commodity futures markets. Journal of Futures Markets, 36, 127-152.

Chuang, C. C., C. M. Kuan and H. Y. Lin (2009) Causality in Quantiles and Dynamic Stock Return-Volume Relations, Journal of Banking and Finance, 33, 1351-1360.

Clark, P. (1973). A subordinated stochastic process model with finite variance for speculative prices, Econometrica, 41, 135-155.

Copeland, T. (1976). A model of asset trading under the assumption of sequential information arrival, Journal of Finance, 31, 1149-1168.

Diks C; Panchenko V, (2005). A note on the Hiemstra-Jones test for Granger non-causality, Studies in Nonlinear Dynamics and Econometrics, vol. 9.

Dwyer, G. P. (2015). The economics of Bitcoin and similar private digital currencies. Journal of Financial Stability, 17, 81-91. 
Fry, J. and Cheah, E-T. (2016). Negative bubbles and shocks in cryptocurrency markets. International Review of Financial Analysis, 47, 343-352.

Gallant, A., Rossi, P., \& Tauchen, G. (1992). Stock prices and volume. Review of Financial Studies, 5, 199-242.

Garcia, D., Tessone, C., Mavrodiev, P. and Perony, N. (2014). The digital traces of bubbles: feedback cycles between socio-economic signals in the Bitcoin economy. Journal of the Royal Society Interface, 11(99), 1-8.

Gebka, B. (2012). The dynamic relation between returns, trading volume, and volatility: Lessons from spillovers between Asia and the United States. Bulletin of Economic Research, 64, 65-90.

Gebka, B., and Wohar, M.E. (2013). Causality between trading volume and returns: Evidence from quantile regressions. International Review of Economics and Finance, 27, 144 159.

Gervais, S., Kaniel, R. and Mingelgrin, D. (2001). The high-volume return premium. Journal of Finance 56, 877-919.

Hanley, B. P. (2013). The false premises and promises of Bitcoin. arXiv preprint arXiv:1312.2048.

Hayes, A.S. (2016). Cryptocurrency value formation: An empirical study leading to a cost of production model for valuing bitcoin. Telematics and Informatics, doi:10.1016/j.tele.2016.05.005.

Hiemstra, C. and Jones, J. D. (1994). Testing for linear and nonlinear Granger causality in the stock price-volume relation. Journal of Finance, 49, number 5, 1639-1664.

Hurvich, C.M. and Tsai, C.-L. (1989). Regression and Time Series Model Selection in Small Samples. Biometrika, 76, 297-307.

Jeong, K., Härdle, W. K. and Song, S., 2012. A consistent nonparametric test for causality in quantile. Econometric Theory, 28, 861-887.

Karpoff, J.M. (1987). The relation between price changes and trading volume: a survey. Journal of Financial and Quantitative Analysis, 22, 109-126.

Kristoufek, L. (2013). BitCoin meets Google Trends and Wikipedia: Quantifying the relationship between phenomena of the Internet era. Scientific Reports 3, Article number: 3415. doi: $10.1038 /$ srep03415

Kristoufek, L. (2014). What are the main drivers of the Bitcoin price? Evidence from wavelet coherence analysis. PLoS ONE 10(4): e0123923. doi:10.1371/journal.pone.0123923 
Li, Q. and Racine, J.S. (2004). Cross-validated local linear nonparametric regression. Statistica Sinica, 14, 485-512.

Li, H., Zhong, W. and Park, S.Y. (2016). Generalized cross-spectral test for nonlinear Granger causality with applications to money-output and price-volume relations. Economic Modelling, 52, 661-671.

Lin, H-Y. (2013). Dynamic Stock Return- Volume Relation: Evidence from Emerging Asian Markets. Bulletin of Economic Research, 65(2), 178-193.

Marsh, T. A. and Wagner, N. (2000). Return-Volume Dependence and Extremes in International Markets. Working Paper RPF-293, Research Program in Finance, University of California, Berkeley.

Nakamoto, S. (2008). Bitcoin: A Peer-to-Peer Electronic Cash System.

Nishiyama, Y., Hitomi, K., Kawasaki, Y., and Jeong, K. 2011. A consistent nonparametric Test for nonlinear causality - specification in time series regression. Journal of Econometrics $165,112-127$.

Polasik, M., Piotrowska, A., Wisniewski, T. P., Kotkowski, R. and Lightfoot, G. (2015). Price Fluctuations and the Use of Bitcoin: An Empirical Inquiry. International Journal of Electronic Commerce, 20(1), 9-49.

Popper, N. (2015). Digital gold: The untold story of Bitcoin. London: Penguin.

Puri, T.N. and Philippatos, G.C. (2008). Asymmetric Volume-Return Relation and Concentrated Trading in LIFFE Futures. European Financial Management, 14, 528 - 563.

Racine, J.S. and Li, Q. (2004). Nonparametric estimation of regression functions with both categorical and continuous data. Journal of Econometrics, 119, 99-130.

Woo, D., Gordon, I. and Iarolov, V. (2013) Bitcoin: A First Assessment. FX and Rates, Global. Bank of America. Merrill Lynch. December.

Yermack, D. (2013). Is Bitcoin a real currency? An economic appraisal (No. w19747). National Bureau of Economic Research. URL: http://www.nber.org/papers/w19747. 


\section{Notes}

1 For a detailed explanation on the negative and positive bubbles in the Bitcoin market, please refer to Fry and Cheah (2016).

2 By the end of June 2016, there were more than 700 cryptocurrencies traded in the market.

3 Hurvich and Tsai (1989) examine the Akaike Information Criterion (AIC) and show that it is biased towards selecting an over-parameterised model, while the SIC is asymptotically consistent.

4 For each quantile, we determine the bandwidth hh using the leave-one-out least-squares cross validation method of Racine and Li (2004) and Li and Racine (2004).

5 Complete details of the unit root tests are available upon request from the authors.

6 While Bitcoin prices from Bitstamp are available as of 13 September 2011, the associated volume data for the period from 13 September 2011 to 19 December 2011 were not usable because they contained many errors, (i.e. values equal to 'infinity'). This led us to start our sample period as of 19 December 2011.

7 The $\chi^{2}(7)$ statistic for the null that returns do not Granger cause volume is 9.9290 with a $p$-value of 0.1926 , that is, returns do not cause volume based on the linear causality test at conventional levels of significance.

8 Similar results were obtained for the AR(7) model of volume, and for the volume equation in the VAR(7) model involving the returns series. Hence, not only is volume nonlinear but it also has a nonlinear relationship with returns, implying non-reliability of the linear test of causality running from returns to volume. Complete details of these results are available upon request from the authors.

9 Based on the suggestion of an anonymous referee, we also conducted the RESET test, and found that both the $\operatorname{AR}(7)$ model of returns and the returns equation in the $\operatorname{VAR}(7)$ model are misspecified irrespective of the order of polynomial specified, that is, based on the highest possible allowed without the test running into singularity issues. Complete details of these results are available upon request from the authors.

10 The AR(7) model for volume, as well as the volume equation in the $\operatorname{VAR}(7)$ model with Bitcoin returns, was found to have a regime change at 22 October 2013. Complete details of these results are available upon request from the authors. Thus, based on the BDS and the structural break tests, we can conclude that traded volume evolves in a nonlinear fashion and is also related nonlinearly to returns.

11 The quantile causality test was been conducted using the open-source software $R$ based on the codes written by the authors. The codes are available upon request.

$12 \mathrm{We}$ also conducted the causality-in-quantiles test with detrended volume and its squared value as dependent variables. However, we could not detect any evidence of causality for either volume or squared volume resulting from returns at any point of the respective conditional distributions of the dependent variables. Complete details of these results are available upon request from the authors. 
APPENDIX

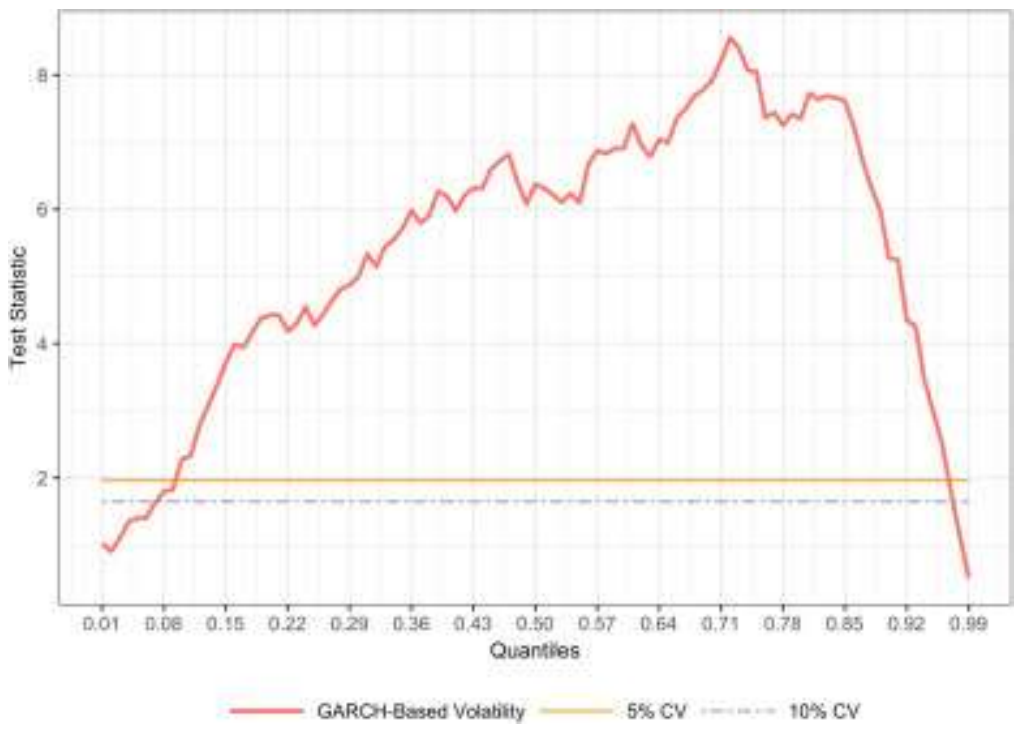

Figure A1. Causality-in-Quantiles: Volume does not Granger cause Bitcoin GARCHBased Volatility

Note: Vertical axis presents the test statistic corresponding to the null the volume does not Granger cause volatility derived from a GARCH $(1,1)$ model; Horizontal axis measures the quantiles; 5 percent critical value is 1.96. 